\title{
Noninvasive Ventilation for Acute Respiratory Failure due to Noncystic Fibrosis Bronchiectasis
}

\author{
Vijay Hadda, Gopal Chawla, Pawan Tiwari, Karan Madan, Maroof Ahmad Khan'1, Anant Mohan, Gopi C. Khilnani, Randeep Guleria \\ Departments of Pulmonary Medicine and Sleep Disorders and 'Biostatistics, All India Institute of Medical Sciences, New Delhi, India
}

\section{Abstract}

Purpose of the Study: Data regarding the use of noninvasive ventilation (NIV) for treatment of acute respiratory failure (ARF) among patients with noncystic fibrosis (CF) bronchiectasis are limited. We intend to describe our experience with NIV use in this setting. Methodology: This was a retrospective study which included 99 patients with bronchiectasis and ARF who required either NIV or invasive mechanical ventilation (IMV). Results: NIV was started as the primary modality of ventilatory support in $81(66.3 \%)$ patients. Fifty-three (65.4\%) patients were managed successfully with NIV. Twenty-eight (34.56\%) patients failed NIV and required endotracheal intubation. Reasons for NIV failure were worsening or nonimprovement of ventilatory or oxygenation parameters $(n=15)$, hypotension $(n=6)$, worsening of sensorium $(n=3)$, and intolerance $(n=4)$. None of the patients failed NIV due to excessive respiratory secretions. The rate of correction of arterial blood gases was comparable between NIV and IMV groups. The total duration of stay (median [interquartile range] days) in hospital was comparable between patients treated with NIV and IMV $(8[7-10]$ vs. $11[5-11] ; P=0.99)$, respectively. The mortality rate between NIV and IMV groups were statistically comparable $(8.64 \%$ vs. $16.6 \% ; P=0.08)$. High APACHE score at admission was associated with NIV failure (odd's ratio [95\% confidence interval]: $1.21(1.07-1.38)$ ]. Conclusions: NIV is feasible for management of ARF with non-CF bronchiectasis. High APACHE may predict NIV failure among these patients.

Keywords: Acute respiratory failure, mechanical ventilation, noncystic fibrosis bronchiectasis, noninvasive ventilation

\section{INTRODUCTION}

Bronchiectasis is a chronic respiratory disease characterized by irreversible dilation of cartilage-containing airways and distortion, inflammation, and mucous plugging of the bronchial tree. ${ }^{[1,2]}$ Its usual clinical features include chronic cough and viscid sputum production. Noncystic fibrosis (CF) bronchiectasis is a disease of heterogeneous etiologies. It was once considered as an orphan disease, however currently it is not so. ${ }^{[3-5]}$ Only in some patients of non-CF bronchiectasis, specific treatment directed to the underlying condition such as allergic bronchopulmonary aspergillosis (ABPA), mycobacterial infection, or immune deficiency may be required. However, in most of the patients, treatment is nonspecific limited to chest physiotherapy to clear the viscid sputum and antibiotics therapy to control the infection, reducing inflammation, and improving bronchial hygiene. Acute worsening and respiratory failure leading to emergency visit and hospitalization is not uncommon among these patients. ${ }^{[6,7]}$ Many of these patients would be

\begin{tabular}{|l|l|}
\hline \multicolumn{2}{|c|}{ Access this article online } \\
\hline Quick Response Code: & Website: \\
\hline & www.ijccm.org \\
\hline & \\
\hline
\end{tabular}

intubated and receive mechanical ventilation for respiratory failure. Endotracheal intubation and mechanical ventilation are associated with increased mortality and morbidity among these patients. ${ }^{[8]}$

Over the last few years, noninvasive ventilation (NIV) has been used successfully for treatment of acute respiratory failure (ARF) due to various diseases without the need for endotracheal intubation and its complications. ${ }^{[9,10]}$ For chronic obstructive pulmonary disease (COPD), NIV is the "standard of care" for management of ARF. ${ }^{[10,11]}$ Bronchiectasis has many features similar to COPD. However, data regarding the use of NIV for treatment of ARF among patients with bronchiectasis are limited. ${ }^{[12]}$

Address for correspondence: Dr. Vijay Hadda, Department of Pulmonary Medicine and Sleep Disorders, All India Institute of Medical Sciences, New Delhi, India. E-mail: vijayhadda@yahoo.com

This is an open access journal, and articles are distributed under the terms of the Creative Commons Attribution-NonCommercial-ShareAlike 4.0 License, which allows others to remix, tweak, and build upon the work non-commercially, as long as appropriate credit is given and the new creations are licensed under the identical terms.

For reprints contact: reprints@medknow.com

How to cite this article: Hadda V, Chawla G, Tiwari P, Madan K, Khan MA, Mohan A, et al. Noninvasive ventilation for acute respiratory failure due to noncystic fibrosis bronchiectasis. Indian J Crit Care Med 2018;22:326-31. 
We report the outcome of patients of non-CF bronchiectasis admitted to our institute with ARF and managed with NIV as a primary mode of ventilatory support. We also compared various physiological and clinical parameter between NIV and mechanical ventilation.

\section{Methodology}

\section{Patient selection}

The records of all admissions and discharges under pulmonary medicine from October 2011 to May 2017 were retrieved, and patients with the diagnosis of bronchiectasis were identified. Patients with bronchiectasis who required admission for reasons other than ARF were excluded. Furthermore, the patients who had ARF but managed with oxygen were excluded from the study. Patients who were admitted with ARF and required either NIV or invasive mechanical ventilation (IMV) were included in the study. The diagnosis of bronchiectasis was based on computed tomographic scan of the thorax showing typical findings. ${ }^{[13]}$ For etiology of bronchiectasis, all patients admitted under pulmonary medicine are routinely evaluated for ABPA, CF, connective tissue disease, mycobacterial infection, and immune deficiency. If the clinical and laboratory workup is negative than it is labeled as idiopathic. For this study, the final diagnoses at the time of discharge were used to classify the etiology of bronchiectasis.

ARF was diagnosed based on the history of acute worsening of cough, breathlessness, respiratory distress or cyanosis and arterial blood gas $(\mathrm{ABG})$ analysis showing either $\mathrm{PaO}_{2}<60 \mathrm{mmHg}$ or $\mathrm{PaCO}_{2}>45 \mathrm{mmHg}$.

\section{Noninvasive ventilation protocol}

At our center, NIV is initiated using orofacial mask. We usually start NIV with inspiratory positive airway pressure (IPAP) of $8-10 \mathrm{~cm}$ of $\mathrm{H}_{2} \mathrm{O}$ and expiratory positive airway pressure of 4-6 cm of $\mathrm{H}_{2} \mathrm{O}$. The patient is closely monitored for clinical stability/improvement, and IPAP is adjusted accordingly. The IPAP is increased by $2-4 \mathrm{~cm}$ of $\mathrm{H}_{2} \mathrm{O}$ every $5-10 \mathrm{~min}$ while observing the use of accessory muscles, respiratory rate, and comfort of the patient. Oxygen is given to keep oxygen saturation between $88 \%$ and $92 \%$. If the patient does not improve even with IPAP of $20 \mathrm{~cm}$ of $\mathrm{H}_{2} \mathrm{O}$ or develop intolerance at any IPAP, we switch to endotracheal intubation and mechanical ventilation. Furthermore, if the patient develops any signs of failure or contraindication of NIV such as hemodynamic instability, decreased mental status, and worsening respiratory acidosis at any time during NIV treatment, we will intubate and start mechanical ventilation. Those patients who stabilized with NIV were treated with NIV for the maximum duration on day 1, allowing breaks for meals and nebulization. Once patient recovered from the acute illness, weaning from NIV is accomplished by gradually increasing the off NIV periods as recommended by the British Thoracic Society. ${ }^{[14]}$

Patients who require endotracheal intubation at any time after commencement of NIV are labeled as failure of NIV.
Data regarding the demography, ABG, APACHE - II score, mode of ventilatory support were retrieved and entered into excel data sheet for analysis.

\section{Statistical analysis}

The data were summarized and analyzed using STATA Version 14 (College Station, TX: StataCorp, LP) software. For analysis, the whole study cohort was divided into two groups - NIV and IMV group, based on the first-line therapy for the management of ARF. Data were expressed as mean \pm standard deviation, median with range or in number and percentage as appropriate. Data were tested for normality using the Kolmogorov-Smirnov test. An independent sample Student's $t$-test was used to compare the parametric values in NIV and IMV group. For comparison of categorical data, the Chi-square test/Fisher's exact test was used to establish the association. The comparison was made between NIV and IMV group with regards to age, gender, etiology, APACHE score, and ABG parameters. To find the early predictor of NIV failure, univariate and multivariate analyses were performed to compare various clinical and $\mathrm{ABG}$ parameters between patients who were successfully managed with NIV as compared to who failed NIV. One way analysis of variance analysis was done for more than two groups with Bonferroni correction. $P<0.05$ was considered to represent statistical significance for the study.

\section{RESULTS}

\section{Study cohort}

There were a total of 134 patients with bronchiectasis who were admitted during the above specified period. Among these, 122 patients were admitted with ARF. Totally 99 patients who required either NIV or IMV constituted the study cohort; whereas patients managed only with oxygen $(n=23)$ were excluded [Figure 1]. The most common etiology of bronchiectasis was post-tuberculosis $(52.45 \%)$ followed by idiopathic (26.22\%), ABPA (16.39\%), and immunodefi ciency (4.91\%). The baseline characteristics of these patients are shown in Table 1.

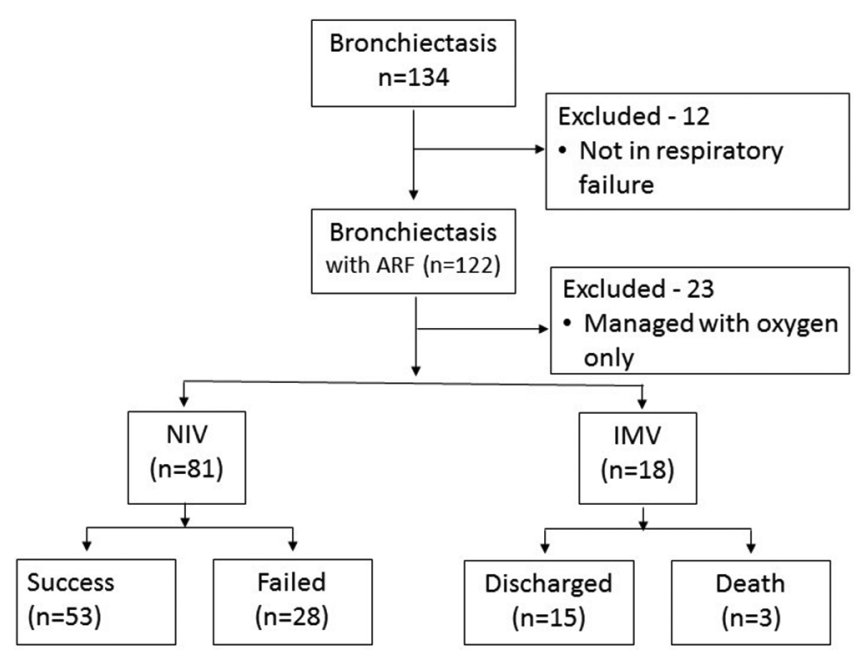

Figure 1: Flow of the patients enrolled in the study 


\section{Trends in arterial blood gas parameters}

The ABGs obtained at the time of admission, $2 \mathrm{~h}, 24 \mathrm{~h}, 48 \mathrm{~h}$, $72 \mathrm{~h}$, day 5,7,10,14 and at the time of discharge or death were compared between NIV and IMV group. Trends and comparison of changes in ABG parameters are shown in Figures 2-5.

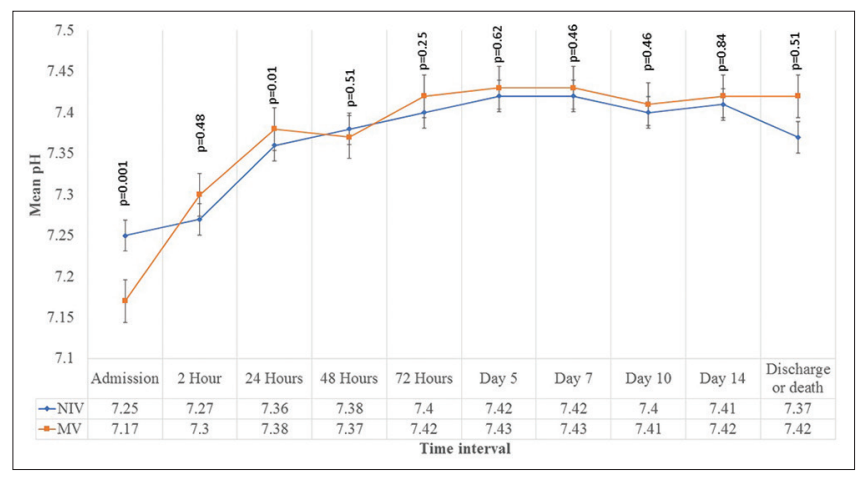

Figure 2: Trends of arterial pH at different time intervals

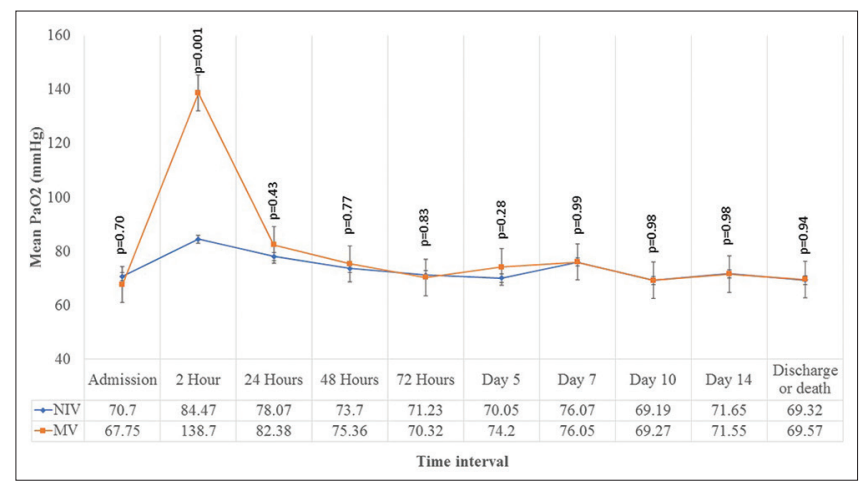

Figure 4: Trends of $\mathrm{PaO}_{2}$ at different time intervals

\section{Outcomes of noninvasive ventilation}

NIV was initiated as first line of ventilatory support for 81 patients. Among these, $53(65.43 \%)$ were managed successfully with NIV. Twenty-eight (34.57\%) patients failed NIV and required endotracheal intubation during the

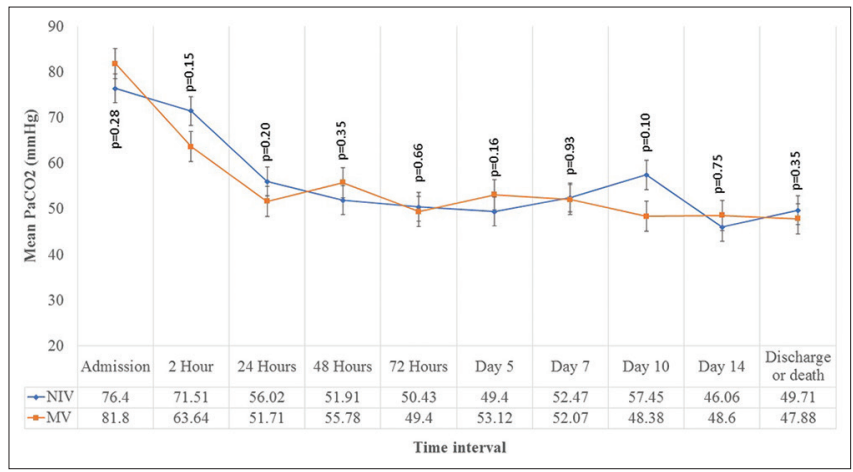

Figure 3: Trends of $\mathrm{PaCO}_{2}$ at different time intervals

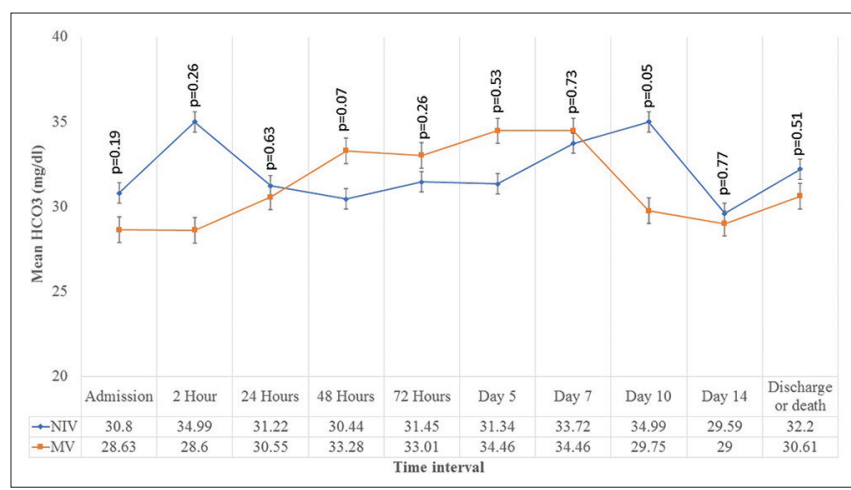

Figure 5: Trends of $\mathrm{HCO}_{3}$ at different time intervals

\section{Table 1: Baseline characteristics of the study cohort}

\begin{tabular}{|c|c|c|c|}
\hline Variables & NIV $(n=81)$ & IMV $(n=18)$ & All patients $(n=122)$ \\
\hline Age (years), mean \pm SD & $47.23 \pm 18.48$ & $50.56 \pm 14.27$ & $45.39 \pm 18.31$ \\
\hline Gender male, $n(\%)$ & $50(61.73)$ & $12(66.6)$ & $73(59.8)$ \\
\hline $\mathrm{APACHE}$, mean $\pm \mathrm{SD}$ & $12.60 \pm 4.24$ & $15.72 \pm 6.05$ & $12.67 \pm 4.84$ \\
\hline Associated COPD, $n(\%)$ & $9(11.1)$ & $4(22.2)$ & $15(12.2)$ \\
\hline \multicolumn{4}{|c|}{ Reason for exacerbation, $n(\%)$} \\
\hline Infective & $71(87.6)$ & $15(83.3)$ & $88(72.1)$ \\
\hline Noninfective & $10(12.4)$ & $3(16.7)$ & $34(27.9)$ \\
\hline \multicolumn{4}{|l|}{ Etiology, $n(\%)$} \\
\hline Posttuberculosis & $42(51.85)$ & $15(83.33)$ & $64(52.46)$ \\
\hline Idiopathic & $16(19.75)$ & $2(11.11)$ & $32(26.22)$ \\
\hline ABPA & $13(16.05)$ & $1(5.56)$ & $20(16.39)$ \\
\hline Immunodeficiency & $5(6.17)$ & 0 & $6(4.92)$ \\
\hline \multicolumn{4}{|c|}{ Arterial blood gases at the time of admission $(\operatorname{mean} \pm \mathrm{SD})$} \\
\hline $\mathrm{pH}$ & $7.25 \pm 0.083$ & $7.17 \pm 0.10$ & $7.25 \pm 0.09$ \\
\hline $\mathrm{PaCO}_{2}(\mathrm{mmHg})$ & $76.40 \pm 19.22$ & $81.87 \pm 21.25$ & $74.02 \pm 22.40$ \\
\hline $\mathrm{PaO}_{2}(\mathrm{mmHg})$ & $70.70 \pm 31.76$ & $67.75 \pm 18.44$ & $70.44 \pm 29.22$ \\
\hline Bicarbonate $(\mathrm{mmHg})$ & $30.81 \pm 6.21$ & $28.63 \pm 7.33$ & $29.65(6.80)$ \\
\hline Oxygen saturation (\%) & $87.14 \pm 7.90$ & $87.37 \pm 8.59$ & $87.67(8.08)$ \\
\hline
\end{tabular}

SD: Standard deviation; NIV: Noninvasive ventilation; IMV: Mechanical ventilation; ABPA: Allergic bronchopulmonary aspergillosis; COPD: Chronic obstructive pulmonary disease; APACHE: Acute physiology and chronic health evaluation 
hospital stay. Reasons for NIV failure were worsening or non-improvement of ventilatory or oxygenation parameters $(n=15)$, hypotension $(n=6)$, worsening of sensorium $(n=3)$, and intolerance $(n=4)$. NIV failure occurred after a median duration of 2.88 (95\% confidence interval [CI]-1.48-4.27) days after the initiation.

The comparison of total duration of stay in hospital, number of days spent on ventilatory support and mortality rate between NIV and IMV are shown in Table 2. There were total 10 deaths in the study group.

Among patients who failed NIV, total days (median [range]) spent on ventilator $(6.5[2-64]$ vs. $6[3-15]$ days; $P=0.45)$, duration (median [range]) of hospital stay (8 [4-64] vs. 11 [5-15] days; $P=0.27)$, and mortality (7 [25\%] vs. $3[16.66 \%] ; P=0.24)$ were comparable to the IMV group. The causes of death among patients who failed NIV were septic shock $(n=4)$ and ventilator-associated pneumonia $(n=3)$.

\section{Predictors of noninvasive ventilation failure}

For identification of the early predictors of NIV failure univariate and multivariate regression analysis was performed using various baseline clinical and laboratory parameters of patients managed successfully with NIV and who failed NIV. The results are summarized in Table 3.

\begin{tabular}{llcc}
\hline Table 2: Comparison of important clinical outcome \\
\hline Outcome parameters & \multicolumn{3}{c}{$\begin{array}{c}\text { Mode of } \\
\text { ventilation }\end{array}$} \\
\cline { 2 - 3 } & NIV & IMV & \\
\hline Days on ventilatory support, median (IQR) & $0(0-3)$ & $4(2-11)$ & $<0.001$ \\
Hospital length of stay (days), median (IQR) & $8(7-10)$ & $11(5-11)$ & 0.99 \\
Mortality, $n$ (\%) & $7(8.64)$ & $3(16.66)$ & 0.08 \\
\hline IQR: Interquartile range; NIV: Noninvasive ventilation; IMV: Mechanical \\
ventilation
\end{tabular}

\begin{tabular}{|c|c|c|c|c|}
\hline \multirow[t]{2}{*}{ Variables } & \multicolumn{2}{|l|}{ Univariate } & \multicolumn{2}{|c|}{ Multivariate } \\
\hline & OR (95\% CI) & $P$ & OR (95\% CI) & $P$ \\
\hline Age (years) & $1.00(0.98-1.03)$ & 0.85 & - & - \\
\hline Gender & $0.56(0.22-1.51)$ & 0.25 & - & - \\
\hline APACHE score & $1.21(1.07-1.38)$ & 0.003 & $1.21(1.07-1.38)$ & 0.003 \\
\hline \multicolumn{5}{|l|}{$\begin{array}{l}\text { Blood gases at } \\
\text { admission }\end{array}$} \\
\hline $\mathrm{pH}$ & $0.017(0.006-4.94)$ & 0.16 & - & - \\
\hline $\mathrm{PaCO}_{2}(\mathrm{mmHg})$ & $1.01(0.98-1.03)$ & 0.45 & - & - \\
\hline $\mathrm{PaO}_{2}(\mathrm{mmHg})$ & $1.02(1.00-1.03)$ & 0.04 & $1.02(1.00-1.034)$ & 0.05 \\
\hline $\begin{array}{l}\text { Bicarbonate } \\
(\mathrm{mmHg})\end{array}$ & $0.99(0.93-1.07)$ & 0.94 & - & - \\
\hline $\begin{array}{l}\text { Oxygen } \\
\text { saturation (\%) }\end{array}$ & $1.02(0.96-1.08)$ & 0.49 & - & - \\
\hline
\end{tabular}

CI: Confidence interval; OR: Odds ratio; APACHE: Acute physiology and chronic health evaluation

\section{Discussion}

Our study results have shown that NIV as the "primary modality" of ventilatory support is feasible for treatment of ARF among patients with non-CF bronchiectasis. Its use was associated with success rate of $65 \%$. The correction of various ABG parameters using NIV at various time intervals was comparable to that of IMV. There were total 10 deaths, 7 in NIV and 3 in IMV group. The duration of hospital stay for NIV was comparable with IMV.

Selection of mode of ventilatory support during ARF among patients with structural lung disease is crucial for optimum outcome. For COPD, NIV remains the mode of the first choice. ${ }^{[10]}$ Patients with bronchiectasis have similar clinical features as COPD, such as cough, breathlessness, and obstructive pattern on spirometry. Many of these patients develop hypoventilation and hypercapnic respiratory failure ${ }^{[12]}$ However, for management of ARF among patients with bronchiectasis NIV is not used routinely. In our study, more than $80 \%(81 / 99)$ patients with bronchiectasis and ARF were given NIV as the first mode of ventilatory support. High rate of NIV use in our study was probably be due to two reasons. First, our hospital is a tertiary care center and we have very good experience of NIV and Intensive Care Unit (ICU) backup, if required. Second, these patients had hypercapnic respiratory failure and there is enough evidence to support NIV use for correction of hypercapnia and respiratory acidosis. ${ }^{[10,11,15]}$ This might have led to use of NIV for bronchiectasis and respiratory failure. Studies have shown that insertion of endotracheal tube in patients with structural lung diseases such as bronchiectasis would result in complications. ${ }^{[16]}$ The successful use of NIV as shown in this study highlights that in almost two-third of the patients with bronchiectasis and ARF the endotracheal intubation may be avoided. Phua et al. reported their experience with NIV for management of 31 patients of non-CF bronchiectasis with ARF. ${ }^{[12]}$ Their success rate of NIV was comparable to our study (67\% vs. 68\%). One of the reasons for not using NIV in patients with bronchiectasis may be the presence of copious amount of sputum. Inability to handle respiratory secretions is one of the contraindications for NIV use. ${ }^{[10,11]}$ However, it should be noted that in this study none of the patients failed NIV due to excessive secretions. These results were consistent with the previous study in which also no patient failed NIV due to inability to handle respiratory secretions. ${ }^{[12]}$

Normalization of the physiological parameters such as blood gas values is also one of the goals of ventilatory support. ${ }^{[17]}$ Longer stay in hospital and ICU has been associated with increased chances of nosocomial infections, increased the cost of care and mortality. ${ }^{[18,19]}$ Faster the normalization of these parameters and early weaning may avoid all these. IMV, due to better control on set variables, is expected to correct both ventilatory and oxygen parameters faster than NIV. However, our study has shown that the various $\mathrm{ABG}$ parameters at 
different time intervals were comparable between patients on NIV and IMV. These results indicate that the rate of correction of ABG parameters similar to IMV may be achieved with NIV without potential complications associated with endotracheal intubation.

One observation in this study which needs to be discussed is the NIV failure. Failure rate of NIV described in patient with COPD and ARF was approximately $20 \% .{ }^{[20]}$ The failure rate of NIV in our study was approximately $34 \%$ which is higher than described in patients with COPD. ${ }^{[20]}$ However, this rate was comparable (34\% vs. $35 \%$ ) to those reported by Phua et al., in patients with bronchiectasis. ${ }^{[12]}$ Both these studies were limited by retrospective study design therefore true association with the outcome is still not known.

Overall mortality in NIV group $(8.6 \%)$ was lower than IMV (16.6\%). In NIV Group, seven patients died and all these had failed NIV and subsequently put on IMV. These results highlight the importance of early identification of the patients who would likely to fail NIV to avoid worse outcome. We tried to find the predictors of early NIV failure. In our study, univariate analysis showed that high APACHE score and worse $\mathrm{PaO} 2$ at the time of admission were associated with failed NIV, however the association was weak. When multiple regression model was applied only high APACHE score was associated with NIV failure (odd's ratio [95\% CI]: 1.21 [1.07-1.38]). These results indicate that APACHE score may be used as a predictor of NIV failure for these patients. Other studies also reported the predictors of NIV failure which included APACHE score, worse hypercapnia, and hypoxemia. ${ }^{[10,12,21]}$ In our study, $\mathrm{PaCO} 2$ and $\mathrm{PaO} 2$ at baseline and at $2 \mathrm{~h}$ were similar in both groups.

Our study also showed that the duration of hospital stay and time spent on ventilator by patients who failed NIV were comparable with the patients who received IMV as first-line management strategy. This implies that the failure of initial trial of NIV among these patients did not impart additional risk of adverse outcome in these patients.

This is one of the largest studies describing the outcome of NIV use in patients with non-CF bronchiectasis and ARF. We would like to acknowledge some limitations of this study. First, being a retrospective study design, it has its inherent limitations. In our study, we could not find the data regarding premorbid conditions, spirometry data of many patients, and amount of sputum production. We use NIV both in ward and ICU therefore we could not report ICU stay separately. The information regarding the presence of associated COPD was limited due to the absence of spirometry. Although this is the largest study till date, however, sample is likely to be small especially for calculation of predictors of NIV failure and mortality. Furthermore, the comparison of mortality rate between NIV and IMV should be done cautiously due to unequal size of two cohorts (81 vs. 19) and only few deaths.

\section{Conclusions}

This retrospective study showed that NIV is feasible and may be used in two-third of patients with non-CF bronchiectasis and ARF. High APACHE at the time of admission may predict the failure of NIV. Failure of NIV did not lead to worse outcome compared to the use of IMV as initial mode of ventilation. Our results suggest that utility of NIV should to be assessed in well-designed prospective studies for ARF in non-CF bronchiectasis patients.

\section{Financial support and sponsorship}

Nil.

\section{Conflicts of interest}

There are no conflicts of interest.

\section{RefERenCes}

1. Bonavita J, Naidich DP. Imaging of bronchiectasis. Clin Chest Med 2012;33:233-48.

2. Dodd JD, Lavelle LP, Fabre A, Brady D. Imaging in cystic fibrosis and non-cystic fibrosis bronchiectasis. Semin Respir Crit Care Med 2015;36:194-206.

3. Barker AF, Bardana EJ Jr. Bronchiectasis: Update of an orphan disease. Am Rev Respir Dis 1988;137:969-78.

4. Bilton D. Update on non-cystic fibrosis bronchiectasis. Curr Opin Pulm Med 2008;14:595-9.

5. Gao YH, Guan WJ, Liu SX, Wang L, Cui JJ, Chen RC, et al. Aetiology of bronchiectasis in adults: A systematic literature review. Respirology 2016;21:1376-83.

6. Seitz AE, Olivier KN, Steiner CA, Montes de Oca R, Holland SM, Prevots DR, et al. Trends and burden of bronchiectasis-associated hospitalizations in the United States, 1993-2006. Chest 2010;138:944-9.

7. Ringshausen FC, de Roux A, Pletz MW, Hämäläinen N, Welte T, Rademacher $\mathrm{J}$, et al. Bronchiectasis-associated hospitalizations in Germany, 2005-2011: A population-based study of disease burden and trends. PLoS One 2013;8:e71109.

8. Alzeer AH, Masood M, Basha SJ, Shaik SA. Survival of bronchiectatic patients with respiratory failure in ICU. BMC Pulm Med 2007;7:17.

9. Agarwal R, Gupta R, Aggarwal AN, Gupta D. Noninvasive positive pressure ventilation in acute respiratory failure due to COPD vs. other causes: Effectiveness and predictors of failure in a respiratory ICU in North India. Int J Chron Obstruct Pulmon Dis 2008;3:737-43.

10. Bello G, De Pascale G, Antonelli M. Noninvasive ventilation. Clin Chest Med 2016;37:711-21.

11. Garpestad E, Brennan J, Hill NS. Noninvasive ventilation for critical care. Chest 2007;132:711-20.

12. Phua J, Ang YL, See KC, Mukhopadhyay A, Santiago EA, Dela Pena EG, et al. Noninvasive and invasive ventilation in acute respiratory failure associated with bronchiectasis. Intensive Care Med 2010;36:638-47.

13. Perera PL, Screaton NJ. Radiological features of bronchiectasis. Eur Respir Monogr 2011;52:44-67.

14. Society BRIGoNiC-BT. The Use of Non-Invasive Ventilation in the Management of Patients with Chronic Obstructive Pulmonary Disease Admitted to Hospital with Acute Type II Respiratory Failure (With Particular Reference to Bilevel Positive Pressure Ventilation); 2008. Availabe from: https://www.brit-thoracicorguk/documentlibrary/clinical-information/niv/niv-guidelines/btsrcpics-guidelineon-niv-in-copd/. [Last accessed on 2017 Jun 29].

15. Gacouin A, Jouneau S, Letheulle J, Kerjouan M, Bouju P, Fillatre P, et al. Trends in prevalence and prognosis in subjects with acute chronic respiratory failure treated with noninvasive and/or invasive ventilation. Respir Care 2015;60:210-8.

16. Walaszek M, Kosiarska A, Gniadek A, Kolpa M, Wolk Z, Dobros W, et al. The risk factors for hospital-acquired pneumonia in the Intensive Care Unit. Przeglad epidemiologiczny 2016;70:15-20, 107-110. 
17. Pierson DJ. Indications for mechanical ventilation in adults with acute respiratory failure. Respir Care 2002;47:249-62.

18. Peñuelas O, Frutos-Vivar F, Fernández C, Anzueto A, Epstein SK, Apezteguía C, et al. Characteristics and outcomes of ventilated patients according to time to liberation from mechanical ventilation. Am J Respir Crit Care Med 2011;184:430-7.

19. Tan SS, Bakker J, Hoogendoorn ME, Kapila A, Martin J, Pezzi A, et al. Direct cost analysis of Intensive Care Unit stay in four European countries: Applying a standardized costing methodology. Value
Health 2012;15:81-6.

20. Lightowler JV, Wedzicha JA, Elliott MW, Ram FS. Non-invasive positive pressure ventilation to treat respiratory failure resulting from exacerbations of chronic obstructive pulmonary disease: Cochrane systematic review and meta-analysis. BMJ 2003;326:185.

21. Corrêa TD, Sanches PR, de Morais LC, Scarin FC, Silva E, Barbas CS, et al. Performance of noninvasive ventilation in acute respiratory failure in critically ill patients: A prospective, observational, cohort study. BMC Pulm Med 2015;15:144. 